\title{
Avaliação da educação superior: Uma análise dos índices de desempenho alcançados pela Universidade do Estado de Mato Grosso e os índices de outras universidades públicas da região Centro-Oeste do Brasil
}

\author{
Lucas dos Reis Carvalho \\ Universidade do Estado de Mato Grosso \\ Brasil \\ Vanusa Batista Pereira \\ Universidade do Estado de Mato Grosso \\ Brasil
}

Data da submissão: 07/06/2018

Data de aceite: 20/02/2019

\begin{abstract}
RESUMO
O objetivo deste estudo foi analisar os índices de desempenho alcançados pela Universidade do Estado de Mato Grosso (Unemat), relativos ao ensino, pesquisa e extensão no ano de 2015, em comparação com os alcançados por outras universidades públicas do Centro Oeste do Brasil. Para tanto, foram coletados dados referentes ao quantitativo referentes a produtividade destas universidades em 2015 e forma aplicados indicadores do Sistema Nacional de Avaliação da Educação Superior (SINAES). Os resultados evidenciaram que a Unemat, mesmo estando em penúltimo lugar quanto à titulação média dos docentes, encontrou-se relativamente bem em ensino (a primeira colocada), e de forma semelhante em extensão (a segunda colocada), contudo teve uma baixa colocação quanto à média de projetos de pesquisa (penúltima colocada).
\end{abstract}

Palavras-chave: Indicadores de desempenho. Produtividade da Unemat. Controle e transparência pública.

\begin{abstract}
The objective of this study was to analyze the performance indexes achieved by the Universidade do Estado de Mato Grosso (Unemat), related to teaching, research and extension in the year 2015, in comparison to those achieved by other public universities in the Center West of Brazil. For that, data referring to the quantitative data regarding the productivity of these universities were collected in 2015 and the indicators of the Sistema Nacional de Avaliação da Educação Superior (SINAES) were applied. The results showed that Unemat, despite being in the penultimate position in the mean titration of teachers, found himself relatively well in teaching (the first place), and similarly in extension (second place), however it had a low placement in the average of research projects (penultimate place).
\end{abstract}

Keywords: Performance indicators. Productivity of Unemat. Control and public transparency. 


\section{INTRODUÇÃO}

Dois dos fatores que determinam a eficiência, eficácia e efetividade de qualquer organização, é o planejamento e o controle dos investimentos, visando os melhores retornos, com o menor custo. No setor público não é diferente, inclusive Barreto Filho (2013) cita que após a inserção da eficiência como princípio explicito da administração pública, surgiram nas entidades públicas como um todo, as metas e avaliações de desempenho, como forma de melhor controlar e direcionar o setor público.

Não obstante a isso estão as universidades, que frente a escassez de recursos, devem avaliar continuamente o Custo x Benefício de suas atividades.

A Universidade do Estado de Mato Grosso (Unemat) é uma instituição de educação superior pública mantida pelo Governo do Estado de Mato Grosso, portanto o Governo e a sociedade, bem como a gestão da própria entidade, devem acompanhar o desenvolvimento/crescimento desta instituição, respeitando a autonomia didático-pedagógica e financeira prevista em lei.

A cultura do gerenciamento dos recursos institucionais (financeiros e humanos), com vistas a promoção de políticas de superação das fraquezas, vem se propagando entre os gestores universitários (MORAIS e SILVA, 2011).

Sano e Montenegro Filho (2013) corroboram com a relevância de uma avaliação contínua e sistemática, com uso de um conjunto harmônico de indicadores, uma vez que esta propicia condições para aumento da eficiência, eficácia e efetividade da formulação e execução das políticas públicas por parte dos gestores.

É importante dizer também que, por outra vertente, Sano e Montenegro Filho (2013) ressaltam a avaliação do desempenho organizacional de entidades públicas como uma forma de controle social, onde o cidadão pode acompanhar e induzir as melhorias nos serviços públicos.

A Unemat, enquanto uma universidade pública multicampi, goza de seu direito constitucional expresso por Brasil (1988, art. 207) como "autonomia didático-científica, administrativa e de gestão financeira e patrimonial", contudo isto não lhe isenta de prestar contas à sociedade quanto ao seu resultado, para que assim haja um maior controle social acerca da gestão e desempenho desta instituição.

Em virtude da relevância/necessidade da avaliação do desempenho organizacional por meio de indicadores, levantou-se a seguinte indagação quanto à problemática: Quais foram os índices de desempenho/produtividade alcançados pela Unemat, relativos ao ensino, pesquisa e 
extensão no ano de 2015, em comparação com os alcançados por outras universidades públicas da região Centro-Oeste do Brasil?

Para solução desta problemática foram determinados os objetivos desta pesquisa. Cumpre observar preliminarmente que Souza et al. (2013) esclarece a definição dos objetivos como sendo a representação do que o pesquisador almeja com seu trabalho e devem responder as questões levantadas pela problemática.

O objetivo geral deste estudo foi analisar os índices de desempenho/produtividade alcançados pela Unemat, relativos ao ensino, pesquisa e extensão no ano de 2015 , em comparação com os alcançados por universidades públicas da região Centro-Oeste do Brasil. Em rápidas pinceladas, Souza et al. (2013) retrata o objetivo geral como a ação necessária para se responder o questionamento proposto para pesquisa.

Valiosa é a contribuição na qual Souza et al. (2013) traz objetivos específicos como as etapas que devem ser cumpridas para se alcançar o objetivo geral.

O primeiro objetivo específico da presente pesquisa foi estabelecer índices de desempenho a partir de um levantamento de dados sobre o quantitativo de projetos de extensão, projetos de pesquisa e quantidade de formandos, referentes ao ano de 2015, da Universidade do Estado de Mato Grosso, bem como de outras universidades estaduais e federais da região Centro-Oeste do Brasil.

Após alcançar-se a etapa anterior, iniciou-se o segundo objetivo que foi comparar os principais índices de produtividade da Unemat com os alcançados pelas outras Instituições de Ensino Superior Públicas (IESP) pesquisadas.

De forma suplementar a análise proposta no objetivo geral, sucedeu-se o terceiro objetivo específico que foi averiguar os reflexos do qualitativo dos docentes da Unemat e demais IESPs com os índices de produtividade encontrados.

Vale ratificar que Freitas Junior (2016) apresenta as medidas de desempenho como os indicadores que trazem numericamente os resultados da organização, quantificando a situação da entidade frente ao cumprimento dos objetivos institucionais.

O autor traz indicadores de desempenho como ferramentas de análise dos resultados obtidos em um determinado período, este tipo de instrumento permite uma maior transparência e controle por parte dos usuários. Assim os usuários internos podem verificar quais pontos mais carecem de melhores políticas, e os usuários externos acompanham a execução dos objetivos da instituição e verificam se a mesma está preparada para maiores investimentos. 
As universidades públicas podem utilizar de indicadores de desempenho como instrumentos de gestão e marketing para suas organizações, e devem, mesmo que respaldadas de autonomia, prestar contas junto a sociedade, transparecendo estes índices ao público.

Salienta-se ainda que Rozados (2005) julga a comparabilidade como pré-requisito para que o indicador torne-se útil, ou seja, um número isolado não proporciona a possibilidade de análise, se não houver um padrão mínimo, uma meta, um acompanhamento histórico, ou ainda os índices de outras entidades que apresentem características semelhantes à instituição avaliada.

A Universidade do Estado de Mato Grosso publica anualmente em seu Portal da Transparência, desde 2004 (UNEMAT, 2015), através da Pró-reitoria de Planejamento e Tecnologia da Informação (PRPTI), um Anuário Estatístico referente ao exercício anterior, com informações desta e de todas as outras pró-reitorias ${ }^{1}$, dados esses que são de suma importância para a instituição. Contudo, estes dados, mesmo que apresentados em forma de indicadores, não têm rigor científico confiável se não houver parâmetros/comparativos.

São nessas premissas (a importância da aplicação de indicadores de desempenho e a necessidade de uma análise comparativa com rigor científico, em especial no setor público) que a relevância da execução deste trabalho se sustenta.

O presente trabalho se delimitou a analisar a produtividade da Unemat em ensino, pesquisa e extensão no exercício de 2015, pois é um período que já tem seus dados apresentados pelas instituições, reduzindo as chances de comprometer o estudo por falta de dados disponíveis.

Além da Unemat, neste estudo foram analisados também os dados de outras universidades da região Centro-Oeste do Brasil (estaduais e federais). São elas: Universidade Federal de Mato Grosso (UFMT), Universidade Federal de Goiás (UFG), Universidade Federal de Mato Grosso do Sul (UFMS), Universidade Estadual de Goiás (UEG) e Universidade Estadual de Mato Grosso do Sul (UEMS). Não foram incluídas as universidades do Distrito Federal, devido ao fato de Brasília, enquanto capital do Brasil, ser uma unidade federativa que não desfruta das mesmas características regionais (políticas, estruturais e econômicas) que as demais localidades do Centro-Oeste do Brasil.

${ }^{1}$ Pró-reitoria de Ensino e Graduação, Pró-reitoria de Extensão e Cultura, Pró-reitoria de Pesquisa e Pósgraduação, Pró-reitoria de Administração, Pró-reitoria de Gestão Financeira, Pró-reitoria de Assuntos Estudantis. 
Nesse estudo não foram abrangidos dados referentes à infraestrutura, retenção, evasão, pós-graduação, pessoal técnico, políticas de assistência estudantil, entre outros fatores de uma IESP, isto devido a delimitação do trabalho e a complexidade em se obter tais informações de tantas instituições. Portanto, este trabalho trata-se do início de uma discussão referente à produtividade da Unemat, e aos motivos que mais influenciam a alta ou baixa produção desta ou até mesmo das outras universidades públicas, federais e estaduais, da região Centro-Oeste do Brasil.

\section{REVISÃO DE LITERATURA}

A contabilidade não deve se restringir ao estudo das demonstrações contábeis, ela deve ir além da valoração em moeda. Isto é melhor evidenciado quando se sai do Segundo Setor (onde o objetivo é puramente o lucro) e entra-se no setor público, por exemplo, onde o bem-estar social é o ponto crucial.

Este trabalho baseou-se em dados não-financeiros, e esta revisão (subdivida em tópicos) traz os conceitos necessários para sua compreensão, ressaltando assuntos como medida de desempenho e sua aplicação no ambiente universitário, levando-se em conta os objetivos destas instituições, em especial da universidade em estudo (Unemat).

\subsection{Medida de desempenho}

Para se trabalhar com medidas de desempenho é necessário conceituar preliminarmente o ato de medir, e Rozados (2005) o retrata como uma atividade rotineira na qual utiliza-se de instrumentos para dar significado à complexidade de um fenômeno.

Em um aprofundamento maior, Rozados (2005) afirma que ciência e tecnologia devem ser mensurados através de múltiplos indicadores, uma vez que estes são reservados justamente para avaliar fenômenos/eventos.

Organizações utilizam de indicadores para analisar seus macro e micro-dados visando regular seus processos na eficiência, eficácia e efetividade exigida no ambiente competitivo da sociedade contemporânea. Corroborando o assunto, Morais e Silva (2011) conceituam eficiência como a capacidade de se realizar uma atividade da melhor maneira possível, eficácia como a capacidade dos resultados auferidos condizerem com as expectativas almejadas, e efetividade como a capacidade do processo contribuir para o alcance dos objetivos da entidade.

Para se obter maior clareza, Campos e Melo (2008) descrevem indicador como uma ferramenta de monitoramento de processos, de forma que os desvios sejam corrigidos e as 
metas alcançadas. Afirmam ainda que esta ferramenta fornece informações úteis para planejamento e gerenciamento dos processos.

Desta forma, observa-se que a análise dos resultados da entidade nas diferentes frentes de atuação, possibilita maior transparência da/para gestão, averiguando quais políticas devem ser melhoradas, quais as fragilidades da instituição, e como as políticas de coerção e as políticas de fomento tem afetado os produtos finais da organização.

É interessante dizer que Crispim e Lugoboni (2012) apresentam indicadores de desempenho como uma ferramenta gerencial de extrema relevância, que devem ser alinhadas a estratégia, missão, e objetivos a serem alcançados. Este gerenciamento por meio de instrumentos de avaliação de desenvolvimento organizacional apresenta-se como um aprimoramento necessário frente a este ambiente cada vez mais competitivo.

Convém ressaltar que Kolody e Luiz (2014) descreve controle social como um complemento ao controle institucional dos órgãos fiscalizadores, representa a sociedade monitorando, e quando necessário intervindo, no planejamento, execução e avaliação da administração pública. A partir destas considerações, nota-se que o uso de indicadores de desempenho representam uma forma de controle social do setor público.

\subsection{Universidades}

As universidades, de acordo com Puhl e Dresch (2016, p. 43), "são o lócus de formação integral da pessoa a qual passa pela tridimensionalidade do fazer universitário, enunciada na legislação pátria”. A partir desta identidade elucidada pelos autores, pode-se notar a importância que estas instituições têm para a sociedade e a sua finalidade, que é proporcionar formação/transformação para as pessoas através do ensino, da pesquisa e da extensão.

É ainda enfatizada a importância destas três dimensões para os acadêmicos:

O ensino situa o estudante na relação com as elaborações e produções científicas existentes, a pesquisa o situa com o seu desenvolvimento intelectual e possibilita a produção de outros saberes e a extensão como situação de confrontação de sua pesquisa com a aprendizagem anterior. Confronta-se na pesquisa e extensão os conhecimentos anteriormente apreendidos com as novas descobertas ou a confirmação do já conhecido. (PUHL; DRESCH, 2016, p. 53).

Observa-se então como a Constituição Federal de 1988 acertou ao determinar estas três vertentes para as universidades, contudo suas ações devem ser planejadas e avaliadas afim de que se obtenha a máxima de resultados e a melhor gestão possível dos recursos disponibilizados. 
De forma mais clara, a extensão, segundo Almeida e Giroto (2007), é a atividade onde a instituição socializa com a sociedade o conhecimento construído, e através disso os acadêmicos e professores melhoram a teoria com a aplicação prática.

É adequado apresentar as considerações de Moita e Andrade (2009) onde pesquisa é a produção do conhecimento científico e o ensino é, enquanto dimensão formativa, o que dá sentido à universidade.

Registre-se ainda que Moita e Andrade (2009) afirmam que é a indissociabilidade destas funções básicas que possibilita uma formação que combina o saber científico com a preocupação referente os problemas sociais contemporâneos.

2.2.1 Gestão de desempenho em universidades

Com vistas ao melhor desempenho de uma organização deve-se ter uma gestão de excelência, e Lira et al. (2013) apontam que existe uma carência na gestão universitária, com falta de profissionalismo e excesso de burocracia. Estes autores apresentam a avaliação por indicadores como ferramenta de apoio às universidades, proporcionando informações necessárias para manter/incentivar o subsídio do ensino superior.

Posta assim a questão, é de se dizer que Cunha (2014) ressalta o foco da avaliação da instituição como sendo o trabalho executado pela organização, e não culpar um sujeito, permitindo a formulação de novas políticas que visem o desempenho da instituição. Com vistas a isto, este trabalho utilizou de macro-dados em seus indicadores, proporcionando uma visão ampla da situação.

Lima (2005) corrobora o assunto apresentando a avaliação como um instrumento que oportuniza a reconstrução das práticas pedagógicas e administrativas da universidade a partir da produção de conhecimento sobre a instituição.

É adequado recordar também que Crispim e Lugoboni (2012) alegam que o aumento da evolução de pesquisas sobre indicadores de desempenho tem-se dado a partir da década de 1990, devido a maior concorrência entre empresas no âmbito global desde este período. Isto justifica a criação do Programa de Avaliação Institucional das Universidades Brasileiras (PAIUB) que, segundo Instituto Nacional de Estudos e Pesquisas Educacionais Anísio Teixeira (Inep) (2009), acontecera em 1993, este programa ia desde a autoavaliação da instituição, até uma avaliação externa da mesma, preocupando-se com o processo e a missão da instituição na sociedade. E, apesar da curta duração, ele contribuiu para legitimar a avaliação como parte da cultura das universidades.

Em 2004, surge então o Sistema Nacional de Avaliação do Ensino Superior (SINAES) como sucessor do PAIUB, este, de acordo com Flores et al. (2012), tem três subsistemas de 
avaliação: a avaliação institucional composta de dois momentos: autoavaliação e avaliação externa; O Exame Nacional de Desempenho de Estudantes (ENADE); e a avaliação dos cursos de graduação. Sendo que este trabalho teve como foco o segundo momento do primeiro subsistema.

Vale recordar que, de acordo com Inep (2015), em 2008 o Ministério da Educação instituiu o Conceito Preliminar do Curso (CPC) para avaliação dos cursos superiores e o Índice Geral dos Cursos (IGC) para avaliação das instituições de educação superior, índices estes que levam em consideração tanto fatores quantitativos quanto qualitativos.

É importante dizer que, Lira et al. (2013) relatam que a maioria dos dados necessários para a composição de indicadores (e, portanto, para a execução desta pesquisa) está disponível em sistemas, e por vezes não são utilizados na tomada de decisão das entidades em decorrência da dificuldade em se manter agilidade nas consultas.

Em consonância com o acatado, deve-se registrar que Lira et al. (2013, p. 2988) transparecem que em universidades: "Esses indicadores devem ser orientados para a busca de uma gestão com qualidade e com isso permitir a busca da competitividade através de ensino diferenciado e com alto nível de qualidade.”. Esta afirmação corrobora com a relevância de estudos como este, bem como reforça a importância de indicadores na tomada de decisão em universidades.

Indubitável é o comentário em que Hoffmann et al. (2014) apresenta a avaliação como um instrumento de controle que enquanto subsídio no processo de tomada de decisão pode direcionar as políticas públicas visando a transformação e melhoria do desempenho de cada Instituição de Ensino Superior (IES).

Em um segundo momento, Hoffmann et al. (2014) relata a necessidade de prestação de contas referente ao ensino superior público, tanto da oferta quanto da qualidade da educação superior, divulgando os principais resultados e balizando-os com padrões de referência que contemplem a realidade atual. Observa-se então que para se avaliar o rendimento da Unemat é necessário que se estipule padrões mínimos que levem em consideração as condições socioeconômicas regionais, para isso será identificado o desempenho de outras universidades públicas da região Centro-Oeste do Brasil, possibilitando a comparação de índices.

\subsubsection{Universidade do Estado de Mato Grosso}

O Instituto de Ensino Superior de Cáceres, hoje intitulado como Universidade do Estado de Mato Grosso, foi criado em 1978, e, segundo Unemat (2016a), apresentava-se em 
2015 como uma organização de treze câmpus, distribuídos nas diversas regiões de Mato Grosso: Alta Floresta, Alto Araguaia, Barra do Bugres, Cáceres, Colíder, Diamantino, Juara, Luciara, Nova Mutum, Nova Xavantina, Pontes e Lacerda, Sinop e Tangará da Serra. Com 14.881 acadêmicos matriculados em seus 65 cursos presenciais de oferta contínua, e 2.468 matriculados em cursos de graduação de modalidades diferenciadas (Ensino à Distância, Turmas Fora de Sede, Educação Indígena e Turmas Parceladas). Fica explicita portanto a tamanha relevância de tal instituição em Mato Grosso.

Além disso, em 2015 a Unemat ainda contava com quinze programas de pósgraduação stricto sensu a nível de Mestrado, quatro doutorados institucionais e três doutorados em rede. (UNEMAT, 2016a).

Ressalta-se também que Unemat (2016a) apresenta um total de R \$275.796.497,57 em despesas empenhadas, $\mathrm{R} \$ 273.944 .656,63$ liquidadas, e $\mathrm{R} \$ 268.257 .562,32$ pagas em 2015 pela Unemat. Tamanho recurso exige um acompanhamento de seus resultados, e por se tratar de uma entidade pública é exigida também uma prestação de contas que vise demonstrar que este investimento está tendo os melhores resultados possíveis, visando assim a satisfação tanto do administrador, como da sociedade.

Segundo dados fornecidos pela Unemat (2016a), o total de despesas empenhadas com investimento em 2015 foi de $\mathrm{R} \$ 1.094 .720,79$, sendo empenhado ainda $\mathrm{R} \$ 235.945 .442,75$ para pagamento de pessoal, e $\mathrm{R} \$ 38.756 .334,03$ para as outras despesas correntes. Com base nisso, nota-se o quão grande é o desafio de se administrar esta organização, exigindo um sistema de informações útil e com métodos de avaliação contínua do desempenho para melhor realizar as tomadas de decisão.

Registre-se que, de acordo com Unemat (2016b), em meados de 2015 a Unemat implantou um sistema integrado de informações gerenciais (administrativas e acadêmicas) aberto ao público que apresenta desde o micro-dado até a consolidação de indicadores, contudo este sistema ainda não teve total preenchimento do seu banco de dados, portanto os dados consolidados, bem como os indicadores disponibilizados, podem não representar fidedignamente a realidade da entidade.

A gestão da Unemat deve prezar e cultuar o acompanhamento contínuo do crescimento e desenvolvimento da instituição, buscando manter a entidade ativa quando confrontada por outros fenômenos concorrentes, seja no setor público ou até mesmo privado. 
Segundo Coelho (1996), o processo de regionalização ocorrido no Brasil buscou dividir seu território em unidades com características que as distinguem, de forma que as

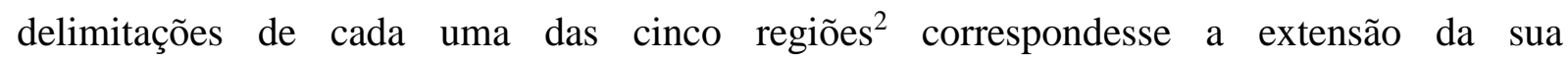
homogeneidade nos aspectos naturais e socioeconômicos.

Diante das prerrogativas acima e com a necessidade de homogeneidade para uma avaliação comparativa interinstitucional, analisou-se também a produtividade de outras universidades públicas, estaduais e federais, do Centro-Oeste, para que sirvam de comparativos, permitindo a visualização do posicionamento da Unemat em um ranking de universidades públicas do Centro-Oeste do Brasil. As universidades utilizadas como comparativos foram: Universidade Federal de Mato Grosso (UFMT), Universidade Federal de Goiás (UFG), Universidade Federal de Mato Grosso do Sul (UFMS), Universidade Estadual de Goiás (UEG) e Universidade Estadual de Mato Grosso do Sul (UEMS).

Em Mato Grosso, além da Unemat, há a UFMT que foi instituída em 10 dezembro de 1970, e em 2015 já contava com câmpus universitários em funcionamento nas cidades de: Cuiabá, Rondonópolis, Sinop, e também o Câmpus Universitário do Araguaia que tem uma unidade em Pontal do Araguaia e outra em Barra do Garças. Além destes câmpus, já está em fase de implantação um novo câmpus em Várzea Grande. Totalizando com todos os câmpus um montante de 18.921 acadêmicos matriculados em cursos presenciais de graduação. (UFMT, 2016).

De acordo com UFMT (2016), esta instituição já dispunha em 2015 de 106 cursos presenciais de graduação, 36 cursos de mestrado e 13 de doutorado.

No Estado de Mato Grosso do Sul há a UFMS no âmbito federal, que foi criada em 05 de julho de 1979, e durante a gestão de 2015, haviam onze câmpus, situados nas cidades de Campo Grande, Aquidauana, Três Lagoas, Paranaíba, Ponta Porã, Coxim, Chapadão do Sul, Nova Andradina, Bonito, Naviraí e Corumbá. Totalizando 18.691 alunos matriculados. E 50 cursos de pós-graduação. (UFMS, 2016).

Ainda em Mato Grosso do Sul existe a UEMS, instituída como universidade desde 20 de dezembro de 1993, e que ofertou em 2015, 58 cursos de graduação, totalizando 7.549 matriculados nos cursos de graduação, isto além de 13 cursos de pós-graduação a nível de mestrado e dois a nível de doutorado, tudo isto distribuído nas unidades universitárias de Amambai, Aquidauana, Campo Grande, Cassilândia, Coxim, Dourados, Glória de Dourados, 
Ivinhema, Jardim, Maracaju, Mundo Novo, Naviraí, Nova Andradina, Paranaíba e Ponta Porã. (UEMS, 2016).

De acordo com UFG (2016), foi criada em 14 de dezembro de 1960 a Universidade Federal de Goiás, e em 2015 a mesma já contava com 102 cursos de pós-graduação stricto sensu, e 148 cursos presenciais de graduação, com um total de 25.860 matriculados, distribuídos no Estado de Goiás, em suas unidades regionais de Goiânia, Catalão, Jataí e cidade de Goiás.

Como fechamento à seção de apresentação das universidades avaliadas, há a UEG, criada em 1999, e que em 2015 já possuía câmpus nas cidades de Anápolís, Aparecida de Goiânia, Caldas Novas, Campos Belos, Ceres, Crixás, Edéia, Formosa, Goianésia, Goiânia, cidade de Goiás, Inhumas, Ipameri, Iporá, Itaberaí, Itapuranga, Itumbiara, Jaraguá, Jussara, Jataí, Luziânia, Minaçu, Mineiros, Morrinhos, Niquelândia, Palmeiras de Goiás, Pires do Rio, Pirenópolis, Porangatu, Posse, Quirinópolis, São Miguel do Araguaia, Sanclerlândia, Santa Helena de Goiás, São Luiz de Montes Belos, Senador Canedo, Silvânia, Trindade e Uruaçu. Em 2015, haviam 16.034 discentes matriculados em cursos presenciais, e foram oferecidos 135 cursos de graduação, 10 cursos de mestrado e nenhum de doutorado. (UEMS, 2016).

\section{METODOLOGIA}

Em função dos objetivos propostos, realizou-se um estudo que Souza et al. (2013) caracteriza como uma pesquisa científica aplicada com abordagem quantitativa, uma vez que utilizou-se de uma análise estatística dos dados para representar a magnitude numérica do desempenho da Unemat. Para tanto foram coletados os seguintes dados de produção da universidade: quantitativo de projetos de extensão; quantitativo de projetos de pesquisa; quantitativo de concluintes de cursos de graduação presencial de oferta contínua.

Para a análise destes dados de produção, foram levantados também alguns dados referentes ao corpo docente e aos cursos. São eles: quantitativo de docentes (efetivos e substitutos); titularidade dos docentes (efetivos e substitutos); quantitativo de cursos de graduação presenciais de oferta contínua que já tenham dado tempo hábil para sua primeira turma completar seu período de integralização.

Em se tratando dos objetivos deste trabalho, pode-se afirmar que se trata de uma pesquisa de análise descritiva, caracterizada por Souza et al. (2013, p.15) como um estudo que “visa identificar e descrever as características de determinada população, indivíduo, local, máquina, empresa ou fenômeno ou o estabelecimento de relações entre variáveis". 
Quanto aos procedimentos, Souza et al. (2013) apresenta-os como sendo próprios de pesquisas bibliográficas e de levantamento, uma vez que foi realizada uma coleta secundária de dados, obtidos através de documentos oficiais emitidos e publicizados pela instituição (Anuários Estatísticos, Relatórios de Gestão e Revistas de divulgação), e quando necessário houve uma coleta primária entrando-se em contato direto com a instituição para solicitar os dados.

\subsection{Procedimentos de análise dos dados}

Após a fase de coleta, os dados foram aplicados em indicadores de desempenho, para se obter os índices de 2015. As fórmulas dos indicadores utilizados são apresentadas no Quadro 01.

Quadro 01: Indicadores utilizados

\begin{tabular}{|l|c|}
\hline \multicolumn{1}{|c|}{ Indicador } & \multicolumn{1}{|c|}{ Fórmula } \\
\hline $\begin{array}{l}\text { Relação entre o total de Projetos de } \\
\text { Pesquisa pelo total de docentes. }\end{array}$ & $\frac{\text { Quantitativo de Projetos de Pesquisa }}{\text { Quantitativo de docentes }}$ X 100 \\
\hline $\begin{array}{l}\text { Relação entre o total de Projetos de } \\
\text { Extensão pelo total de docentes. }\end{array}$ & $\frac{\text { Quantitativo de Projetos de Extensão }}{\text { Quantitativo de docentes }}$ \\
\hline $\begin{array}{l}\text { Relação entre o total de concluintes pelo } \\
\text { total de cursos. }\end{array}$ & $\begin{array}{c}\text { Quantitativo de Concluintes } \\
\text { Quantitativo de cursos que tenham dado tempo } \\
\text { para uma turma formar }\end{array}$ \\
\hline
\end{tabular}

Fonte: Unemat, 2016b, com adaptações.

Os primeiros dois indicadores utilizados neste trabalho (Relação do total de projetos de extensão pelo total de docentes e Relação do total de projetos de pesquisa pelo total de docentes) visaram obter uma relação entre a produtividade de pesquisa e extensão e o corpo docente da instituição ${ }^{3}$, eles foram extraídos do portfólio do Sistema Nacional de Avaliação da Educação Superior (SINAES), e foram escolhidos justamente por representarem diretamente a situação de duas das três vertentes analisadas e por comporem parte de um instrumento do sistema que acompanha/realiza a avaliação de todas as entidades de educação superior do Brasil, inclusive, segundo Brasil (2004), este sistema tem, entre outros objetivos, os de avaliar a educação superior e os cursos de graduação. Com estes indicadores obteve-se a

\footnotetext{
${ }^{3}$ Para este estudo levou-se em consideração tanto os docentes efetivos, quanto os interinos, uma vez que ambos gozam das mesmas obrigações dentro da entidade.
} 
média de projetos, de pesquisa e de extensão, por docente, que é justamente o profissional destinado à elaboração e ao desenvolvimento destas atividades.

Ressalta-se ainda estes indicadores surgiram antes mesmo do SINAES, pois já eram utilizados pelo PAIUB, e com a criação do SINAES estes indicadores quantitativos continuaram a ser utilizados (UNEMAT, 2002, 2016b).

Além dos indicadores do SINAES, também foi apresentada (no terceiro indicador) a relação entre o total de concluintes de cursos de graduação presencial de oferta contínua pelo total de cursos de graduação presenciais de oferta contínua que já tenham dado tempo hábil para sua primeira turma completar sua integralização. Com este índice pode-se observar quantos acadêmicos, em média, a Unemat está continuamente disponibilizando para o mercado com o nível de graduado.

$\mathrm{Na}$ análise apresentada por Unemat (2002) verificou-se que estes indicadores foram criados para uma análise histórica (onde os parâmetros são os resultados alcançados em períodos anteriores) ou interinstitucional (onde os parâmetros são os resultados obtidos por outras instituições que tenham características semelhantes), isto se deve pelo fato de não haver padrões oficiais estipulados por órgãos reguladores.

A partir da afirmação anterior, houve a necessidade de aplicar esta mesma metodologia nas demais universidades, estaduais e federais, do Centro-Oeste do Brasil ${ }^{4}$ de forma paralela ao levantamento destes índices na Unemat, construindo assim pontos de referência para análise do desenvolvimento da Unemat frente aos índices alcançados por outras universidades desta região.

Da mesma forma que na Unemat, os dados das demais universidades avaliadas foram pesquisados inicialmente através de uma pesquisa secundária nos documentos oficiais publicizados, e quando o dado não estava disponível nos documentos entrou-se em contato direto com estas outras instituições, através de e-mail e também pelo Sistema Eletrônico do Serviço de Informação ao Cidadão (e-SIC) $)^{5}$.

Logo após foi averiguado o nível de titulação dos docentes das instituições (porcentagem de docentes mestres/doutores e porcentagem de docentes doutores), para então realizar o cruzamento dos índices alcançados, com a titulação do corpo docente e assim verificar se a titulação dos docentes impacta na produtividade da instituição.

\footnotetext{
${ }^{4}$ Universidade Federal de Mato Grosso, Universidade Federal de Goiás, Universidade Federal de Mato Grosso do Sul, Universidade do Estado de Goiás, Universidade do Estado de Mato Grosso do Sul.

${ }^{5}$ Sistema utilizado para solicitação formal de dados às entidades da esfera federal.
} 


\section{RESULTADOS E DISCUSSÕES}

A pesquisa secundária realizada em anuário e relatórios de gestão apresentou-se como insuficiente, pois faltaram alguns dados necessários para a pesquisa, acarretando em uma pesquisa primária complementar através de contato direto com as universidades. Vale ressaltar que quando os dados obtidos apresentavam divergência optou-se por utilizar os dados da pesquisa primária.

No tópico abaixo apresenta-se mais detalhadamente quais foram os dados alcançados e quais as suas fontes. Este é acompanhado de um segundo tópico que elucida a análise dos dados.

\subsection{Coleta de dados}

O Anuário Estatístico da Unemat 2016 (Ano-base 2015) foi o documento base para obtenção dos dados da Unemat. Inicialmente foram pesquisados os dados de produção que seguem na Tabela 01 .

Tabela 01 - Dados de produtividade da Unemat em 2015

\begin{tabular}{l|c}
\hline Tipo de produção & Quantitativo \\
\hline Projetos de Pesquisa & 346 \\
\hline Projetos de Extensão & 276 \\
\hline Concluintes de curso de graduação presencial de oferta contínua & 2668 \\
\hline
\end{tabular}

Fonte: Unemat (2016a).

A Unemat desenvolveu, durante o ano de 2015, 622 projetos, sendo 346 de pesquisa e 276 de extensão. Além destas atividades em pesquisa e extensão, também houve produção final com relação ao ensino, uma vez que 2.668 acadêmicos colaram grau em 2015. Estes dados necessitam da complementação apresentada na Tabela 02 para que a produção seja relacionada a magnitude da instituição.

Tabela 02 - Quantitativo de docentes e cursos da Unemat em 2015

Quantitativo de docentes Quantitativo de cursos de graduação presencial de oferta contínua

\begin{tabular}{l|r}
1398 & 51
\end{tabular}

Fonte: Unemat (2016a).

Com relação aos docentes, observa-se que a Unemat dispôs em 2015 de 1.398 profissionais docentes destinados a disseminação de ensino, pesquisa e extensão. E os 2.668 acadêmicos que concluíram sua graduação, são originados de 51 cursos desta IESP. 
Com vistas a produzir referenciais comparativos, as Tabelas 03 e 04 apresentam os dados obtidos nas outras universidades estaduais e federais do Centro-Oeste do Brasil, mediante aplicação da mesma metodologia empregada no levantamento dos dados da Unemat.

Tabela 03 - Dados de Produtividade das outras universidades estudadas, em 2015

\begin{tabular}{l|c|c|c}
\hline Instituição & $\begin{array}{l}\text { Projetos de } \\
\text { Pesquisa }\end{array}$ & $\begin{array}{l}\text { Projetos de } \\
\text { Extensão }\end{array}$ & $\begin{array}{l}\text { Concluintes de curso de } \\
\text { graduação presencial de oferta } \\
\text { contínua }\end{array}$ \\
\hline UFMT (UFMT, 2016, 2017a) & 2500 & 346 & 2385 \\
\hline UFG (UFG, 2016, 2017) & 2566 & 159 & 645 \\
\hline UFMS (UFMS, 2016, 2017a) & 798 & 190 & 2712 \\
\hline UEG (UEG, 2016, 2017) & 429 & 520 & 915 \\
\hline UEMS (UEMS, 2016) & 303 & 150 & \\
\hline
\end{tabular}

Fonte: Elaborado pelo autor com base na literatura.

Observa-se que em um mesmo período há variação de produção de uma instituição para outra, isto se justifica pela quantidade de docentes (efetivos e substitutos) e cursos de cada entidade que é evidenciada na tabela a seguir.

Tabela 04 - Quantitativo de docentes e cursos das outras universidades estudadas, em 2015

\begin{tabular}{l|c|c}
\hline \multicolumn{1}{c|}{ Universidade } & $\begin{array}{c}\text { Quantitativo de } \\
\text { docentes }\end{array}$ & $\begin{array}{c}\text { Quantitativo de cursos de graduação } \\
\text { presencial de oferta contínua }\end{array}$ \\
\hline UFMT (UFMT, 2016, 2017b) & 1800 & 92 \\
\hline UFG (UFG, 2016) & 2389 & $*$ \\
\hline UFMS (UFMS, 2017a, 2017b) & 1395 & 138 \\
\hline UEG (UEG, 2017) & 2000 & 51 \\
\hline UEMS (UEMS, 2016, 2017) & 788 & \\
\hline
\end{tabular}

Fonte: Elaborado pelo autor com base na literatura.

Notas:

*Dado não obtido.

Mesmo com contato direto via e-mail e sistema, a UFG não disponibilizou, em tempo hábil, o quantitativo de cursos de graduação presencial de oferta contínua. A falta destes dados não só prejudica os estudos científicos que os utilizam, mas também é um afronte a Lei de Transparência que deve possibilitar a população em geral acompanhar não só os investimentos que estão feitos, mas também os rendimentos que estão sendo alcançados, inclusive Brasil (2011) elucida nos incisos V e VI do seu artigo $7^{\circ}$ que as organizações da 
administração pública, direta e indireta, devem assegurar aos cidadãos o acesso as informações referentes aos serviços prestados, bem como a utilização dos recursos público.

\subsection{Análise dos dados}

A partir dos dados coletados realizou-se o processamento/análise destes dados. A mesma é apresentada nos tópicos a seguir. Optou-se por realizar uma estruturação da análise dos dados em três tópicos, sendo que cada tópico corresponde a um objetivo específico da pesquisa.

\subsubsection{Levantamento dos índices}

Os dados coletados propiciaram a aplicação dos indicadores, na Tabela 05, verificamse os índices obtidos pelo cruzamento dos dados da Unemat.

Tabela 05 - Índices alcançados pela Unemat em 2015

\begin{tabular}{l|c}
\hline \multicolumn{1}{c|}{ Indicador } & Índice alcançado \\
\hline Relação entre o total de Projetos de Pesquisa pelo total de docentes. & $24,75 \%$ \\
\hline Relação entre o total de Projetos de Extensão pelo total de docentes. & $19,74 \%$ \\
\hline Relação entre o total de concluintes pelo total de cursos. & 52,314 \\
\hline
\end{tabular}

Fonte: Dados da pesquisa, 2017.

A Tabela 05 revela que, em 2015, a Unemat obteve um índice de 24,75\% em pesquisa e 19,74\% em extensão, ou seja, a Unemat desenvolveu em média 24,75 projetos de pesquisa e 19,74 projetos de extensão a cada cem docentes. Em se tratando do ensino, a média geral dos $\operatorname{cursos}^{6}$ em que esta universidade atestou o conhecimento, com o título de graduado em 2015, foi de 52,314 formandos.

Os índices das demais instituições pesquisadas são apresentados na Tabela 06 a seguir:

Tabela 06 - Índices alcançados pelas outras universidades estudadas, em 2015

\begin{tabular}{l|c|c|c|c|c}
\hline \multicolumn{1}{c|}{ Indicador } & UFMT & UFG & UFMS & UEG & UEMS \\
\hline $\begin{array}{l}\text { Relação entre o total de Projetos de } \\
\text { Pesquisa pelo total de docentes. }\end{array}$ & $138,89 \%$ & $107,41 \%$ & $57,20 \%$ & $21,45 \%$ & $38,45 \%$ \\
\hline $\begin{array}{l}\text { Relação entre o total de Projetos de } \\
\text { Extensão pelo total de docentes. }\end{array}$ & $19,22 \%$ & $6,66 \%$ & $13,62 \%$ & $26,00 \%$ & $19,04 \%$ \\
\hline $\begin{array}{l}\text { Relação entre o total de concluintes pelo } \\
\text { total de cursos. }\end{array}$ & 25,924 & $*$ & 17,648 & 19,652 & 17,941 \\
\hline
\end{tabular}

\footnotetext{
${ }^{6}$ Esta análise delimitou-se a utilizar somente os cursos presenciais de oferta contínua e os concluintes destes cursos, uma vez que cursos em modalidades diferenciadas (como educação a distância, por exemplo) têm características específicas, que se desconsideradas comprometeriam a cientificidade da pesquisa por desprezo de variáveis relevantes.
} 
Fonte: Dados da pesquisa, 2017.

Notas:

*Índice não levantado por falta de dados.

A falta de dados da Universidade Federal de Goiás apresentada na Tabela 04 comprometeu o levantamento do índice da Relação entre o total de concluintes pelo total de cursos da mesma, contudo este empecilho não desconfigurou a pesquisa, pois restaram outros quatro pontos de referência para análise do desempenho da Unemat nestes índices.

\subsubsection{Comparativo dos índices}

A partir do levantamento dos índices pôde-se analisar a situação da Unemat em relação aos resultados das outras instituições. Esta análise é demonstrada nos Gráficos 01 a 03.

Gráfico 01 - Índices da Relação entre o total de Projetos de Pesquisa pelo total de docentes das Universidades estudadas, em 2015

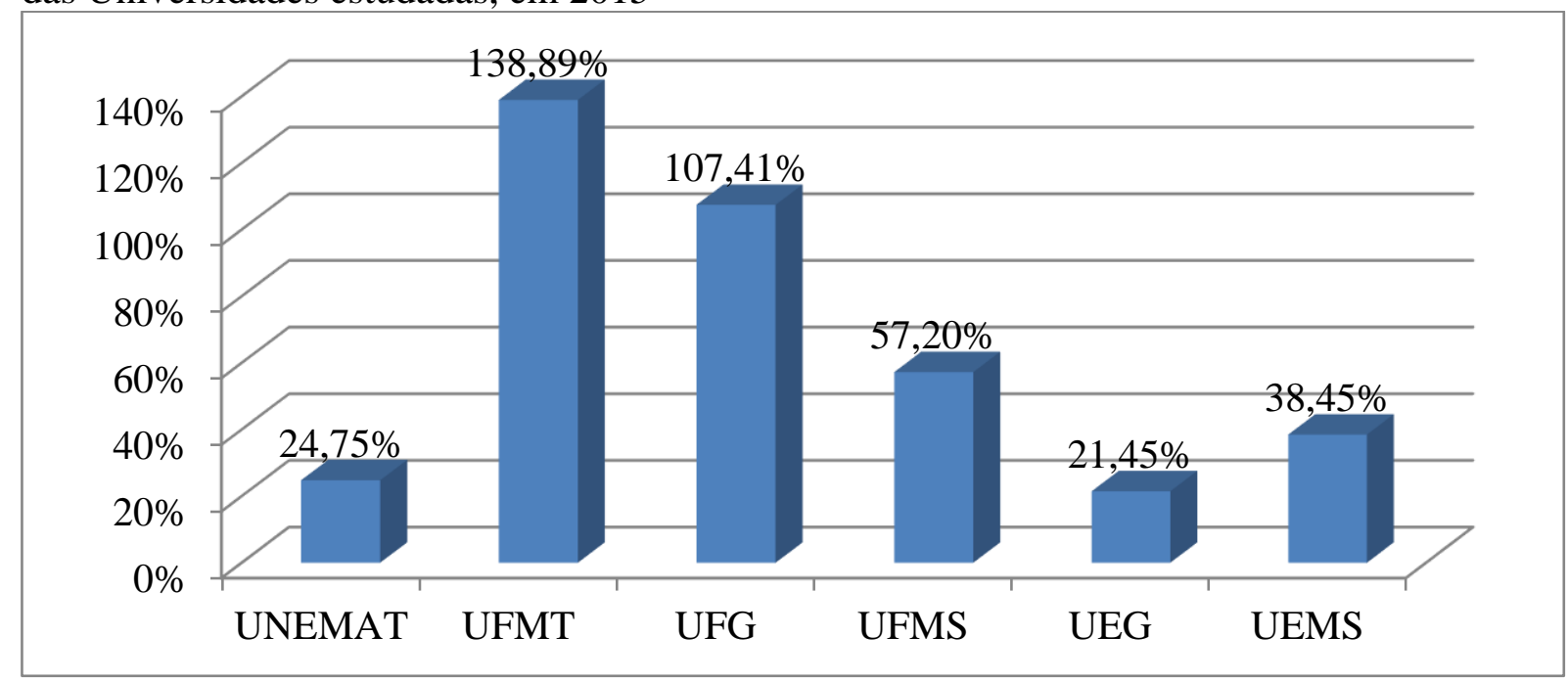

Fonte: Dados da pesquisa, 2017.

Ressalta-se no Gráfico 01 que a Unemat, de acordo com a polaridade trabalhada por Unemat (2016b, p. 66) de que "quanto maior, melhor”, não apresenta uma boa colocação no indicador de pesquisa, estando em $5^{\circ}$ lugar no desenvolvimento de projetos de pesquisa (penúltimo lugar) entre as entidades pesquisadas, superando apenas o índice da Universidade Estadual de Goiás. Esta informação, segundo Cunha (2014), deve repercutir como a necessidade de novas políticas de fomento à pesquisa e não em punições individuais pelo ocorrido. 
Gráfico 02 - Índices da Relação entre o total de Projetos de Extensão pelo total de docentes das Universidades estudadas, em 2015

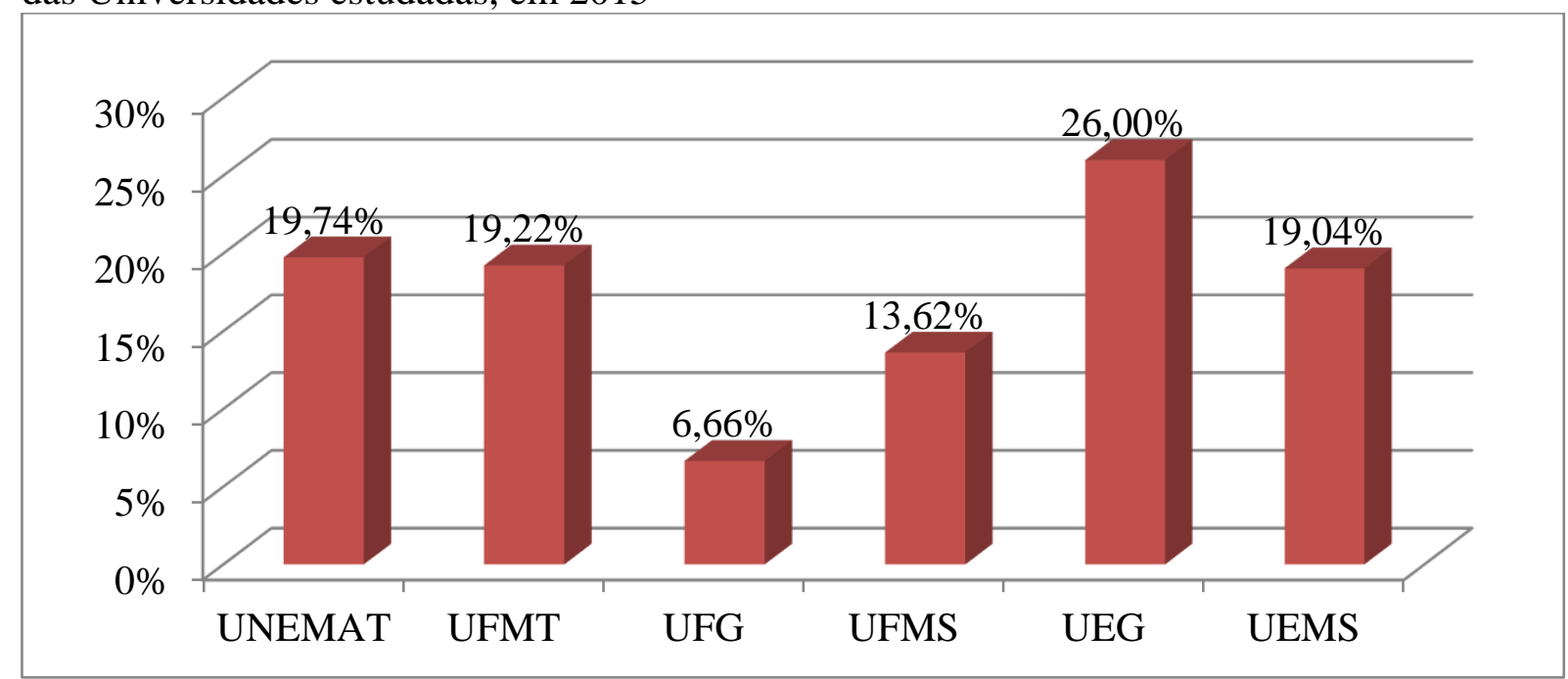

Fonte: Dados da pesquisa, 2017.

A partir da análise comparativa proposta por Unemat (2002) e da polaridade apresentada por Unemat (2016b, p. 66) de que neste indicador "quanto maior melhor", nota-se no Gráfico 02 um quadro diferente para a extensão, onde a Unemat encontra-se com a segunda colocação, perdendo apenas para a UEG que apresentou em 2015 um índice de 26\%, frente ao índice de $19,74 \%$ da Unemat.

Gráfico 03 - Índices da Relação entre o total de concluintes pelo total de cursos das Universidades estudadas, em 2015

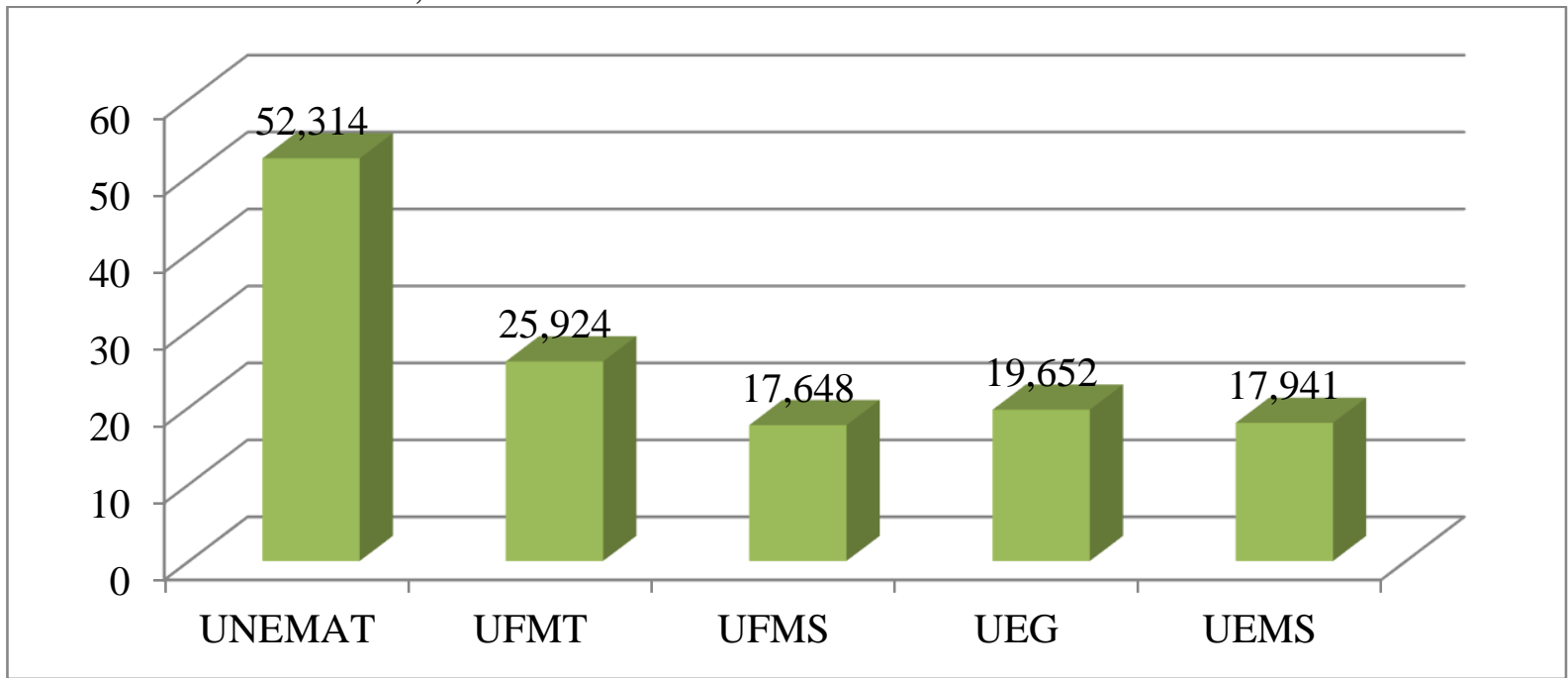

Fonte: Dados da pesquisa, 2017.

Em relação aos índices evidenciados no Gráfico 03, observa-se que, quanto ao ensino em 2015, a Unemat esteve, quantitativamente, melhor que as demais IESPs utilizadas neste estudo, alcançando mais que o dobro do índice auferido pela segunda colocada.

Se a situação averiguada com a análise dos índices obtidos não tiver a devida atenção, pode acarretar numa formação acadêmica que Moita e Andrade (2004) descrevem como uma 
formação de indivíduos preocupados com as questões sociais, mas que não conseguem construir conhecimento científico para auxiliá-los.

\subsubsection{Reflexos da titulação docente}

De forma complementar, avaliou-se também a titulação do corpo das universidades que compõem o escopo deste trabalho, observa-se os dados levantados na tabela a seguir:

Tabela 07 - Titulação do corpo docente das universidades estudadas, em 2015

\begin{tabular}{l|c|c|c|c}
\multicolumn{1}{c|}{ Universidade } & Graduados/Especialistas & Mestres & Doutores & Total \\
\hline UNEMAT (UNEMAT, 2016a) & 393 & 580 & 425 & 1398 \\
\hline UFMT (UFMT, 2017b) & 122 & 481 & 1197 & 1800 \\
\hline UFG (UFG, 2016) & 41 & 543 & 1805 & 2389 \\
\hline UFMS (e-SIC, 2017b) & 43 & 221 & 1131 & 1395 \\
\hline UEG (UEG, 2017) & 978 & 662 & 360 & 2000 \\
\hline UEMS & $*$ & $*$ & $*$ & $*$ \\
\hline
\end{tabular}

Fonte: Elaborado pelo autor com base na literatura.

Notas:

*Dado não obtido.

A Tabela 07 apresenta os dados brutos que foram obtidos referente a titulação dos professores das universidades avaliadas. Nota-se a falta dos dados da Universidade Estadual de Mato Grosso do Sul, contudo UEMS (2017) justifica que não dispõe destes dados pois não realiza o acompanhamento da titulação do docentes interinos, isto se dá em decorrência do Plano de Cargos e Salários da carreira docente na instituição não diferenciar os docentes interinos por titulação, ou seja, a UEMS não tem o controle do nível do corpo docente interino porque isto não impacta diretamente no Grupo de Despesas Pessoal e Encargos da entidade.

A partir deste levantamento, pôde-se processar os dados e alcançar os percentuais expostos abaixo:

Tabela 08 - Percentual de corpo docente mestre/doutor das universidades estudadas, em 2015

\begin{tabular}{l|c|c|c|c|c|c}
\hline \multicolumn{1}{c|}{ Titulação } & UNEMAT & UFMT & UFG & UFMS & UEG & UEMS \\
\hline Mestres/doutores & $71,89 \%$ & $93,22 \%$ & $98,28 \%$ & $96,92 \%$ & $51,10 \%$ & $*$ \\
\hline Doutores & $30,40 \%$ & $66,50 \%$ & $75,55 \%$ & $81,08 \%$ & $18,00 \%$ & $*$ \\
\hline
\end{tabular}

Fonte: Dados da pesquisa, 2017.

O processamento dos dados da Tabela 07 originou a Tabela 08 , onde os dados são apresentados em forma de percentuais acerca do quantitativo de professores considerados com 
alto nível de qualificação ${ }^{7}$ em relação ao total de docentes de cada instituição (efetivos e substitutos) em 2015.

A seguir se expõem de forma gráfica os dados processados dos docentes mestres/doutores em relação aos demais, para assim propiciar uma melhor visão da situação.

Gráfico 04: Percentual de docentes com mestres/doutores

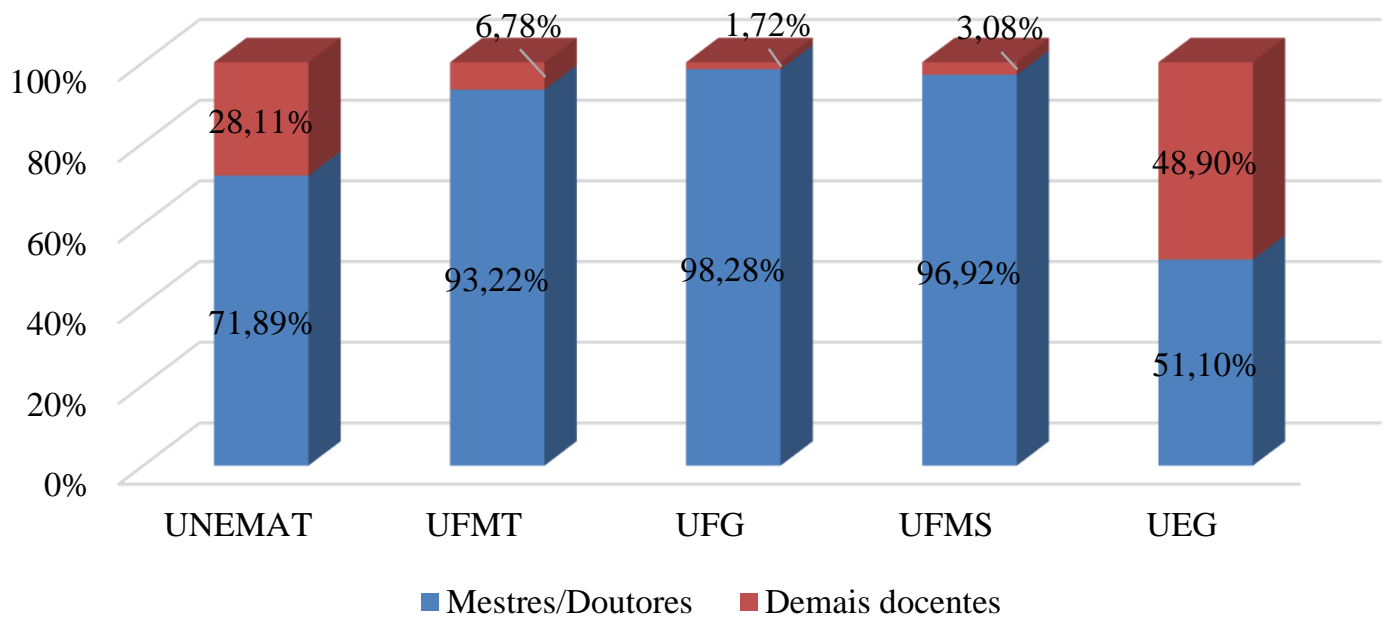

Fonte: Dados da pesquisa, 2017.

No Gráfico 04, não teve uma situação muito confortável em 2015, pois 28,11\% dos seus docentes eram apenas especialistas ou ainda graduados, estando entre as duas universidades com pior percentual, entre as quatro apresentadas.

A seguir apresentam-se graficamente os dados processados dos docentes doutores em relação aos demais.

7 Para o estudo, considera-se como alto nível de titulação os docentes mestres e doutores que, segundo Coordenação de Aperfeiçoamento de Pessoal de Nível Superior (Capes) (1965), são profissionais com uma pósgraduação mais vinculada à pesquisa e ao meio acadêmico, e mesmo quando se tratam de mestrados e doutorados profissionais. 
Gráfico 05: Percentual de docentes doutores

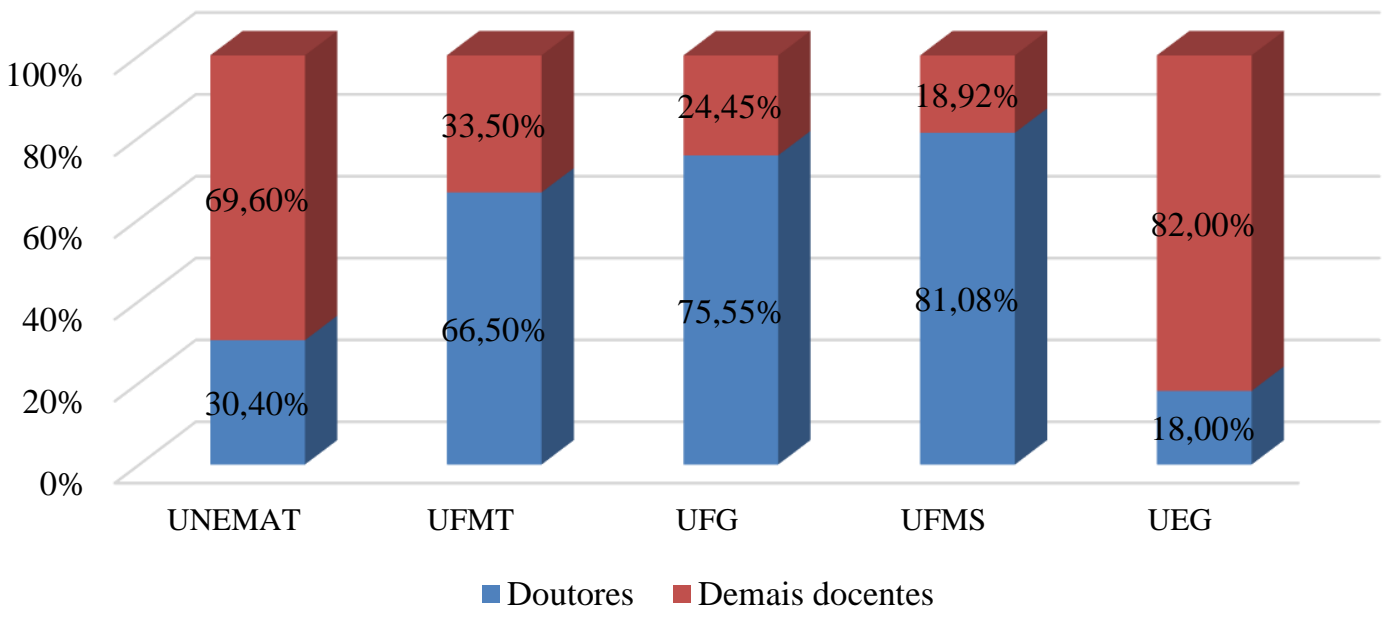

Fonte: Dados da pesquisa, 2017.

No quinto gráfico a situação é ainda mais gritante, pois somente 30,4\% dos docentes da Unemat eram doutores em 2015, frente a outras universidades que tiveram percentuais de $75,55 \%$ e $81,08 \%$.

A partir de nossa análise de desempenho, pôde-se estruturar o ranking apresentado no quadro a seguir, com base nesta apresentação nota-se de maneira mais holística a situação atual das universidades.

Quadro 02: Ranking das universidades estudadas

\begin{tabular}{|l|l|l|l|l|l|}
\hline Colocação & Ensino & Pesquisa & Extensão & $\begin{array}{c}\text { Docentes } \\
\text { (mestres/doutores) }\end{array}$ & $\begin{array}{c}\text { Docentes } \\
\text { (doutores) }\end{array}$ \\
\hline $1^{\text {o }}$ & UNEMAT & UFMT & UEG & UFG & UFMS \\
\hline $2^{\text {o }}$ & UFMT & UFG & UNEMAT & UFMS & UFG \\
\hline $3^{\text {o }}$ & UEG & UFMS & UFMT & UFMT & UFMT \\
\hline $4^{\text {o }}$ & UEMS & UEMS & UEMS & UNEMAT & UNEMAT \\
\hline $5^{\text {o }}$ & UFMS & UNEMAT & UFMS & UEG & UEG \\
\hline $6^{\circ}$ & & UEG & UFG & & \\
\hline
\end{tabular}

Fonte: Dados da pesquisa, 2017.

Observa-se claramente como a relativa baixa titulação do corpo docente das universidades estaduais (que é o caso da Unemat) não impactou diretamente o desempenho em ensino e extensão, tal afirmação não pode ser feita à produção de pesquisa, uma vez que as universidades federais (que são as IESPs que apresentaram melhor titulação do corpo docente) tiveram melhor desempenho na pesquisa. Esta análise teve como respaldo a afirmação de Lima et al. (2009), de que análises sociais quantitativas visam descrever os fatos estatisticamente e elaborar teorias que estabeleçam relações de causalidade entre as variáveis. 


\section{CONSIDERAÇÕES FINAIS}

Práticas administrativas de avaliação contínua são úteis em qualquer organização, elas permitem uma melhor gestão dos recurso, e no caso de entidades públicas, também oferece uma maior transparência aos cidadãos que passam a observar quais os rendimentos/finalidade dos seus tributos.

A partir da execução do primeiro objetivo específico desta pesquisa, que visa justamente a medida quantitativa dos resultados que a Unemat obteve em 2015, constatou-se que esta instituição teve em 2015 um índice de 24,75\% na relação entre o total de projetos de pesquisa pelo total de docentes, e 19,74\% na relação entre o total de projetos de extensão pelo total de docentes, e além destes índices referentes aos projetos, alcançou-se uma média geral de 52,314 na relação entre o total de concluintes pelo total de cursos.

Em se tratando do segundo objetivo específico, que busca a comparação dos índices de desempenho da Unemat em 2015 com os índices das outras IESPs estudadas, averiguou-se que no fator pesquisa a Unemat esteve em uma situação não muito agradável, pois obteve a quinta colocação entre os seis índices levantados. Na extensão, a Unemat atingiu a segunda colocação de um grupo de seis índices, estando portanto acima do índice mediano. Com relação ao ensino, observou-se uma situação relativamente confortável para a Unemat, pois a mesma teve o maior índice de formandos por curso entre as cinco instituições avaliadas. $\mathrm{O}$ índice da relação entre o total de concluintes pelo total de cursos da UFG não foi calculado por falta de resposta em tempo hábil à solicitação de dados realizada, a instituição ultrapassou inclusive o prazo de 30 dias previsto em lei. (BRASIL, 2011).

No terceiro, e último, objetivo específico ${ }^{8}$ evidenciado no Quadro 02 verificou-se que as universidades federais têm um corpo docente mais qualificado (a Unemat obteve a quarta colocação nas duas análises de titulação realizadas) e isto impacta diretamente na produção de pesquisa, onde as universidades federais ocuparam as primeiras colocações, esta relação da titulação com os projetos de pesquisa pode ser devido ao fato da maioria dos editais dos órgãos de fomento à pesquisa serem restritos a professores doutores efetivos. Em se tratando de extensão, constatou-se uma situação contrária, uma vez que as duas universidades estaduais tiveram maior desempenho neste indicador, e o índice da terceira estadual perdeu a terceira colocação por aproximadamente $0,18 \%$. Retratando que os docentes com menor qualificação têm dado preferência para a área da extensão. No ensino não observou-se uma

\footnotetext{
${ }^{8}$ Averiguar os reflexos do qualitativo dos docentes da Unemat e demais IESPs com os índices de produtividade encontrados.
} 
relação direta da titulação de docentes com o índice de formandos por curso (a Unemat, por exemplo, teve o melhor índice mesmo apresentando percentuais de titulação docente inferiores a quase todas as universidades pesquisadas). Em resposta à solicitação de informações sobre titulação dos docentes a UEMS informou apenas a titulação dos docentes efetivos, e devido à falta deste acompanhamento aos docentes interinos, esta instituição foi desconsiderada na análise da titulação dos docentes.

Com base neste estudo, realizado com os dados de 2015, constatou-se que a produção de pesquisa na Unemat em 2015 carece de maior atenção, e uma das formas de fomento pode ser investindo na qualificação de seu corpo docente, quanto a extensão e ao ensino verificouse uma situação relativamente confortável em 2015, e não foi encontrado indício de que a maior titulação do corpo docente impacta, direta e isoladamente, em uma maior produção de ensino e extensão.

Espera-se que as evidências apontadas contribuam com a literatura existente sobre o tema, salientando a necessidade do controle na gestão pública, bem como apresentando qual a situação atual da Unemat frente a outras IESPs.

Este estudo trouxe o início da discussão acerca do controle, incentivo e gestão do desempenho de universidades públicas, recomenda-se novos estudos quantitativos e qualitativos, quanto ao impacto no desempenho da instituição causado por fatores relacionados a infraestrutura, orçamento, tabela salarial dos servidores, entre outras variáveis que afetam as universidades.

\section{REFERÊNCIAS BIBLIOGRÁFICAS}

ALMEIDA, N. F.; GIROTO, A. P. S. Extensão universitária como diretriz da disseminação de conhecimentos. In: Encontro de Iniciação Científica das Faculdades Integradas "Antonio Eufrásio de Toledo", 2007. Anais eletrônicos... Disponível em:

<http://intertemas.unitoledo.br/revista/index.php/ETIC/article/view/1473/1406>. Acesso em 09 jun. 2017.

BARRETO FILHO, S. A. O estudo dos Princípios da Eficiência, Eficácia e Economicidade na Administração Pública. Revista Âmbito Jurídico, Rio Grande, 2013. Disponível em: <http://www.ambito-juridico.com.br/site/?n_link=revista_artigos_leitura\&artigo_id=12851>. Acesso em 19 out 2016.

BRASIL. Constituição (1988). Constituição da República Federativa do Brasil de 1988. Disponível em:

<http://www.planalto.gov.br/ccivil_03/constituicao/constituicaocompilado.htm>. Acesso em 19 out. 2016.

Lei no 10.861 de 14 de abril de 2004. Institui o Sistema Nacional de Avaliação da Educação Superior - SINAES e dá outras providências. Disponível em: 
<http://www.planalto.gov.br/ccivil_03/_ato2004-2006/2004/lei/110.861.htm>. Acesso em 26 out. 2016.

Lei $\mathrm{n}^{\circ}$ 12.527, de 18 de novembro de 2011. Regula o acesso a informações previsto no inciso XXXIII do art. $5^{\circ}$, no inciso II do $\S 3^{\circ}$ do art. 37 e no $\S 2^{\circ}$ do art. 216 da Constituição Federal; altera a Lei no 8.112, de 11 de dezembro de 1990; revoga a Lei no 11.111, de 5 de maio de 2005, e dispositivos da Lei no 8.159, de 8 de janeiro de 1991; e dá outras providências. Disponível em: <http://www.planalto.gov.br/ccivil_03/_ato20112014/2011/lei/l12527.htm>. Acesso em 15 mai. 2017.

CAMPOS, L. M. S.; MELO, D. A. Indicadores de desempenho dos Sistemas de Gestão Ambiental (SGA): uma pesquisa teórica. Revista Produção, 2008. Disponível em: <http://www.scielo.br/pdf/prod/v18n3/a10v18n3.pdf >. Acesso em 10 jun. 2017.

COELHO, M. A. Geografia do Brasil. 4 ed. rev., atual. e ampl. São Paulo - SP: Moderna, 1996.

COORDENAÇÃO DE APERFEIÇOAMENTO DE PESSOAL DE NÍVEL SUPERIOR (CAPES). Parecer n⿳ 977/65. Definição dos cursos de pós-graduação. Disponível em: <http://capes.gov.br/images/stories/download/avaliacao/avaliacao-n/Parecer-977-1965.pdf>. Acesso em 03 jun. 2017.

CRISPIM, S.; LUGOBONI, L. Avaliação de desempenho organizacional: Análise comparativa dos modelos teóricos e pesquisa de aplicação nas Instituições de Ensino Superior da Região Metropolitana de São Paulo. Revista Portuguesa e Brasileira de Gestão, 2012. Disponível em: <http://www.scielo.mec.pt/scielo.php?script=sci_arttext\&pid=S164544642012000100005 >. Acesso em 19 out. 2016.

CUNHA, M. I. A qualidade e ensino de graduação e o complexo exercício de propor indicadores: é possível obter avanços?. Revista Avaliação, Sorocaba, 2014. Disponível em: < http://www.scielo.br/pdf/aval/v19n2/a11v19n2.pdf>. Acesso em 09 nov. 2016.

FLORES, R. D. et al. Sistemas de avaliação de desempenho da educação superior no Brasil. In: Congresso Internacional de Administração, 2012. Gestão Estratégica:

Empreendedorismo e Sustentabilidade. Disponível em:

<http://www.sigmees.com.br/files/ARTIGO\%20ADMPG\%20COM\%20NOMES.pdf>. Acesso em 10 nov. 2016.

FREITAS JUNIOR, V. Ontologia para representação semântica de indicadores de desempenho considerando aspectos de vaguidade, temporalidade e relacionamento entre indicadores. 2016. Tese (Doutorado em Engenharia e Gestão do Conhecimento) - Programa de Pós-Graduação em Engenharia e Gestão do Conhecimento, Universidade Federal de Santa Catarina, Florianópolis, 2016. Disponível em:

$<$ https://repositorio.ufsc.br/bitstream/handle/123456789/168163/339508.pdf?sequence=1\&is Allowed=y $>$. Acesso em 27 jun. 2017.

HOFFMANN, C. et al. O desempenho das universidades brasileiras na perspectiva do Índice Geral de Cursos (IGC). Revista Educação e Pesquisa, São Paulo, 2014. Disponível em: <http://www.scielo.br/scielo.php?script=sci_arttext\&pid=S1517-97022014000300005>. Acesso em 11 nov. 2016. 


\section{INSTITUTO NACIONAL DE ESTUDOS E PESQUISAS EDUCACIONAIS ANÍSIO} TEIXEIRA (INEP). SINAES - Sistema Nacional de Avaliação da Educação Superior Da Concepção à Regulamentação. Instituto Nacional de Estudos e Pesquisas Educacionais Anísio Teixeira. 5 ed. Brasília-DF, 2009.

Indicadores de Qualidade. Brasília-DF, 2015. Disponível em:

<http://webcache.googleusercontent.com/search?q=cache:9RqXKOirxcMJ:portal.inep.gov.br/ indicadores-de-qualidade $+\& \mathrm{~cd}=4 \& \mathrm{hl}=\mathrm{pt}-\mathrm{BR} \& \mathrm{ct}=\mathrm{clnk} \& \mathrm{gl}=\mathrm{br}>$. Acesso em 08 ago. 2017.

KOLODY, A.; LUIZ, D. E. C. Controle social: entre a contradição e a complementaridade. Serviço Social em Revista, Londrina, 2014. Disponível em: <http://www.uel.br/revistas/uel/index.php/ssrevista/article/view/16668/15190>. Acesso 30 jun. 2017

LIMA, E. G. S. Avaliação Institucional: Discutindo concepções, enfoques e fundamentos teórico/metodológicos. Revista da Faculdade de Educação, Unemat, 2005. Disponível em: <http://www2.unemat.br/revistafaed/content/vol/vol_4/artigo_4/65_89.pdf >. Acesso em 29 jun. 2017.

LIMA, E. G. S. et al. O embate qualitativo/quantitativo no processo de avaliação. Revista da Faculdade de Educação, Unemat, 2009. Disponível em: <http://www2.unemat.br/revistafaed/content/vol/vol_11/artigo_11/81_96.pdf >. Acesso em 30 jun. 2017.

LIRA, A. M. et al. Aplicações do conceito de qualidade no ensino superior. Revista Enciclopédia Biosfera, Goiânia, 2013. Disponível em: <http://www.conhecer.org.br/enciclop/2013b/CIENCIAS\%20HUMANAS/APLICACOES.pd f>. Acesso em 09 nov. 2016.

MOITA, F. M. G. S. C.; ANDRADE, F. C. B. Ensino-pesquisa-extensão: um exercício de indissociabilidade na pós-graduação. Revista Brasileira de Educação, 2009. Disponível em: <http://www.scielo.br/pdf/rbedu/v14n41/v14n41a06.pdf>. Acesso em 30 jun. 2017.

MORAIS, S. M. L.; SILVA, A. C. A Prática Gerencial das Instituições Federais de Ensino Superior Avaliadas em Cinco Dimensões. Revista Meta: Avaliação, 2011. Disponível em: <http://revistas.cesgranrio.org.br/index.php/metaavaliacao/article/view/112/135>. Acesso em 29 mai. 2017.

PUHL, M. J.; DRESCH, O. I. O princípio da indissociabilidade entre ensino, pesquisa e extensão e o conhecimento. Revista DI@LOGUS, 2016. Disponível em: <http://revistaeletronica.unicruz.edu.br/index.php/Revista/article/view/3991/728>. Acesso em 19 out. 2016.

ROZADOS, H. B. F. Uso de indicadores na gestão de recursos de informação. Revista Digital de Biblioteconomia e Ciência da Informação, Campinas, 2005. Disponível em: <https://periodicos.sbu.unicamp.br/ojs/index.php/rdbci/article/view/2054/2184>. Acesso em 11 jun. 2017. 
SANO, H.; MONTENEGRO FILHO, M. J. F. As Técnicas de Avaliação da Eficiência, Eficácia e Efetividade na Gestão Pública e sua Relevância para o Desenvolvimento Social e das Ações Públicas. Revista Desenvolvimento em Questão, Editora Unijuí, 2013.

Disponível em:

<https://www.revistas.unijui.edu.br/index.php/desenvolvimentoemquestao/article/view/186/5 64>. Acesso em 07 jun. 2017.

SOUZA, D. I. et al. Manual de orientações para projetos de pesquisa. Fundação Escola Técnica Liberato Salzano Vieira da Cunha, 2013. Disponível em:

$<$ http://liberato.com.br/sites/default/files/manual_de_orientacoes_para_projetos_de_pesquisa. pdf>. Acesso em 04 nov. 2016.

UNIVERSIDADE DO ESTADO DE MATO GROSSSO (UNEMAT). Avaliação

Institucional da Unemat: Relatório-síntese da auto-avaliação. Universidade do Estado de Mato Grosso. Cáceres - MT, 2002.

Transparência Pública. 2015. Disponível em:

$<$ http://portal.unemat.br/?pg=site\&i=transparencia-publica\&m=institucional \&c=anuarioestatistico>. Acesso em 26 out. 2016.

Anuário da UNEMAT 2016 Ano-base 2015. Universidade do Estado de Mato Grosso, 2016a. Disponível em: <http://portal.unemat.br/?pg=site\&i=transparenciapublica\&m=institucional\&c=anuario-estatistico $>$. Acesso em 29 jan. 2017.

. Documento Final do Planejamento Estratégico Participativo 2015-2025.

Universidade do Estado de Mato Grosso, 2016b. Disponível em:

$<$ http://portal.unemat.br/media/files/Documento\%20Final\%20PEP\%20CONSUNI\%20-10-1016.pdf>. Acesso em 12 mai. 2017.

UNIVERSIDADE ESTADUAL DE GOIÁS (UEG). Relatório de Autoavaliação

Institucional 2015. Anápolis, GO, 2016. Disponível em:

$<$ https://issuu.com/gerenciadeavaliacaoinstitucional/docs/relatorio_autoavalia_ao_2015_ueg _1>. Acesso em 09 jan. 2017.

Solicitação de dados para pesquisa. [mensagem pessoal]. Mensagem recebida por <ger.avaliacaoinstitucional@ ueg.br>em 23 mai. 2017.

UNIVERSIDADE ESTADUAL DE MATO GROSSO DO SUL (UEMS). Relatório de Atividades 2015. Universidade Estadual Mato Grosso do Sul, 2016. Disponível em: <http://www.uems.br/assets/uploads/proap/planejamento/1_2016-12-16_15-01-10.pdf>. Acesso em 09 jan. 2017.

Solicitação de dados para pesquisa. [mensagem pessoal]. Mensagem recebida por <prodhs@uems.br>em 26 mai. 2017.

UNIVERSIDADE FEDERAL DE GOIÁS (UFG). Relatório de Gestão do Exercício de 2015. Universidade Federal de Goiás, 2016.

Relatório. [mensagem pessoal], 2017. Mensagem recebida por <helio.proec@gmail.com> em 30 jun. 2017. 
UNIVERSIDADE FEDERAL DE MATO GROSSO (UFMT). Anuário Estatístico 2016 Ano-base 2015. Universidade Federal de Mato Grosso, 2016. Disponível em:

<http://www.ufmt.br/proplan/arquivos/c9d0a7b9237b7651112ddc3e3c3534e2.pdf>. Acesso em 09 jan. 2017.

Solicitação de dados para pesquisa. [mensagem pessoal], 2017a. Mensagem recebida por<geyce@ufmt.br> em 22 mai. 2017.

Solicitação de quantitativo de docentes (efetivos e interinos) por titulação referente ao ano de 2015. [Sistema e-SIC], 2017b. Protocolo 23480013125201704. Resposta recebida em 19 jun. 2017.

UNIVERSIDADE FEDERAL DE MATO GROSSO DO SUL (UFMS). Relatório de Gestão 2015. Universidade Federal de Mato Grosso do Sul, 2016. Disponível em:

<https://www.ufms.br/wp-content/uploads/2016/04/Relat\%C3\%B3rio-Gest\%C3\%A3o-2015UFMS.pdf>. Acesso em 09 jan. 2017.

Pesquisa. [mensagem pessoal], 2017a. Mensagem recebida por <digad.prograd@ufms.br>em 19 mai. 2017.

Solicitação de quantitativo de docentes (efetivos e interinos) por titulação

referente ao ano de 2015. [Sistema e-SIC], 2017b. Protocolo 23480013126201741. Resposta recebida em 30 mai. 2017. 